Research, part of a Special Feature on Assessing Risks to Wildlife

\title{
A Framework for Spatial Risk Assessments: Potential Impacts of Nonindigenous Invasive Species on Native Species
}

\author{
$\underline{\text { Craig R. Allen }}^{1}, \underline{\text { Alan R. Johnson }}^{2}$, and $\underline{\text { Leslie Parris }}^{2}$
}

\begin{abstract}
Many populations of wild animals and plants are declining and face increasing threats from habitat fragmentation and loss as well as exposure to stressors ranging from toxicants to diseases to invasive nonindigenous species. We describe and demonstrate a spatially explicit ecological risk assessment that allows for the incorporation of a broad array of information that may influence the distribution of an invasive species, toxicants, or other stressors, and the incorporation of landscape variables that may influence the spread of a species or substances. The first step in our analyses is to develop species models and quantify spatial overlap between stressor and target organisms. Risk is assessed as the product of spatial overlap and a hazard index based on target species vulnerabilities to the stressor of interest. We illustrate our methods with an example in which the stressor is the ecologically destructive nonindigenous ant, Solenopsis invicta, and the targets are two declining vertebrate species in the state of South Carolina, USA. A risk approach that focuses on landscapes and that is explicitly spatial is of particular relevance as remaining undeveloped lands become increasingly uncommon and isolated and more important in the management and recovery of species and ecological systems. Effective ecosystem management includes the control of multiple stressors, including invasive species with large impacts, understanding where those impacts may be the most severe, and implementing management strategies to reduce impacts.
\end{abstract}

Key Words: declining species; invasive species; nonindigenous species; risk assessment; spatial risk.

\section{INTRODUCTION}

Risk assessment is the process of obtaining quantitative or qualitative measures of risk levels (EPA 1998). Risk assessments have traditionally focused on quantifying the probability of negative consequences from one or a number of identified or unknown sources. This probabilistic risk assessment has been the focus of engineers and mathematicians (Seife 2003). Fields such as toxicology have built on the probabilistic risk tradition and applied probabilistic methods of assessing risks posed by toxicants to humans and wild animals. Consequently, much of the risk assessment literature has been focused on assessing potential impacts of chemical stressors on animals and humans. Technological advances in spatial assessments, and theoretical advances in landscape ecology, now enable an explicit consideration of the spatial nature of many risks, and risks posed from sources other than chemicals (Hayes 2002). The application of the risk assessment paradigm to invasive species is an example of this widening scope of analysis (Andersen et al. 2004).

Many wildlife populations are declining and face increasing threats from habitat fragmentation and loss, as well as exposure to stressors ranging from toxicants to diseases to invasive nonindigenous species. These sources of risk may interact. For example, fragmentation of habitat may increase the distribution and abundance of many invasive plants (With 2002, 2004). There is a need to develop methodologies that incorporate spatial analysis into the assessment of risk from multiple stressors, applicable to a large number of potentially affected species. 


\section{METHODS}

We describe and demonstrate a spatially explicit ecological risk assessment method that closely conforms to the general framework developed for the assessment of risks due to environmental toxicants (EPA 1998). The risk assessment progresses through the sequential phases of (1) problem formulation, (2) risk analysis, and (3) risk characterization. Our approach allows for the incorporation of a broad array of information describing factors that may influence the distribution of an invasive species, toxicants, or other stressors, and the incorporation of landscape variables that may influence the spread of a species or substance. Because of the incorporation of landscape metrics and the spatial nature of the analyses, the models may be used to explore alternative scenarios of landscape change, restoration, or results of differing policy interventions. We illustrate our methods with an example using the state of South Carolina, USA as our study area, an invasive ant species as our environmental stressor, and two declining native vertebrates as our targets of interest. Our example is provided for illustrative rather than prescriptive purposes. This methodology was developed to sift among a large number of potentially impacted species to identify those species most at risk, thereby enabling scarce resources to be more effectively targeted toward the analysis of potentially deleterious stressor effects on those species most at risk. Thus, this method is a preliminary "coursefilter" approach. After species most at risk have been identified, further assessment of risk is desirable.

Invasive nonnative species negatively impact a number of vertebrate and invertebrate species, and by direct or indirect means may change ecological process, structure, and function (Vitousek et al. 1996, Mack and D'Antonio 1998). For more than half of the vertebrate species recently extinct, invasive nonnative species are a major cause of decline, second only to habitat loss (Pimentel et al. 2000). Several investigators have explored the use of risk analysis techniques for nonchemical stressors such as invasive species and genetically modified organisms (e.g., Groves et al. 2001, Bartell and Nair 2004, Landis 2004). We examine a nonnative species of particular concern in the southeastern United States, the red imported fire ant, Solenopsis invicta (Wojcik et al. 2001).

We use the term target species or target group to refer to taxa under consideration for potential impacts of invasive, nonindigenous species. Rare, endangered, or threatened species represent animals with small or declining populations, for which additional stressors may be a proximate cause of extinction. Although most general assessments of historic extinctions list habitat loss and invasive species as the first and second most frequent cause of species extinctions, respectively (Pimentel et al. 2000 ), in reality these two sources of proximate extinction risk are highly related. Habitat degradation, disturbance, and fragmentation not only cause extinctions directly, but also aid the process of invasion. Thus, a spatially based risk assessment process is ideally suited to assessing the risk of invasive species to endangered or declining species.

In our spatial risk analysis procedure, the initial assessment endpoint is the probability of spatial cooccurrence of the stressor or stressors with the distribution of the target species. Clearly, for invasive species to have direct, deleterious impacts on a target species, their spatial distributions must overlap. However, the demonstration of overlapping distributions is not in itself sufficient evidence to conclude that the target species will be impacted. Thus, this initial level of analysis eliminates combinations of invasive and target species that fail to co-occur, but combinations that do overlap are subjected to the next tier of analysis.

In the second tier of our risk analysis, the assessment endpoints include declines in abundance of target species, decreases in the area occupied by the target species, and/or loss of functional connectivity in the target species' use of the landscape. These endpoints are of clear ecological relevance, and are likely to be important to managers interested in conservation of the target species. Given sufficient time and knowledge, it is possible to quantitatively estimate stressor-induced changes in abundance for some target species through, for example, population viability analyses. However, our method is meant to rapidly sort through a large number of potentially impacted species to identify those most at risk. Therefore, we develop a semi-quantitative index of effects based on categorical ratings of various types of impact. This is similar to the rank-based approach to regional risk assessment developed by Landis and Wiegers (1997), and proposed for application to invasive species by Landis (2004).

Although our measurement endpoints do not furnish 
quantitative estimates of changes in target species abundance, they allow species to be ranked according to the probable impact of invaders on each target species. For selected species, for which demographic data are available, and for which reasonable estimates of changes in demographic parameters due to stressors can be adduced, one may assess population viability in the presence of each stressor, i.e., singly and in combination. The assessment endpoint for population viability analysis is the probability of extinction within each patch of habitat or over some regional extent.

Co-occurrence of invasive and target species is assessed on the basis of predictive models calibrated with field data. Logistic regression models can be used to predict the probability of species occurrence in various habitats (Pearce and Ferrier 2000); previous studies have demonstrated the utility of logistic regression for this purpose (Li et al. 1997, Forys et al. 2002). Similarly, classification and regression tree (CART) models (Clark and Pregibon 1992) can be used to predict species abundances within the habitats in which they occur. This approach was used by Iverson and Prasad (1998) to predict tree species abundance in response to climate change. Spatial co-occurrence (Allen et al. 2001) and relative abundances of invader and target species can be estimated by overlaying the predictions of the logistic regression or CART models within a GIS (Forys et al. 2002).

For most target species, it is not possible to derive precise quantitative estimates of the effects of invasive species. Instead, a "hazard index" may be assigned to each invasive/target species pair. This hazard index is developed based on conceptual models of invasive/target species interactions. For each species pair, each possible interaction is assessed as likely or unlikely, yielding a score of 1 or 0 (Table 1). The scores can be conveniently represented in a matrix format, analogous to the matrix approach discussed in Foran and Ferenc (1999). The hazard index is calculated by summing the scores for each interaction, normalized by dividing by the number of interactions. Although this is not directly interpretable in terms of predicted population-level consequences, it provides a comparable set of values, which allows ranking of target species in terms of the likely magnitude of impact. The use of such qualitative approaches in ecological risk assessment is well established (Foran and Ferenc 1999). Such qualitative methods have been applied to predicting the risk of spread of introduced species (USDA 1993, USFWS/ NOAA 1996, Pheloung et al. 1999). Landis and Wiegers (1997) have developed a qualitative risk assessment approach based on the ranking of sources, habitats, and impacts.

\section{RESULTS}

\section{Example of risk assessment procedures}

The red imported fire ant, Solenopsis invicta, is an established, aggressive nonindigenous species in the southeastern United States. Originally introduced to the port of Mobile, Alabama, USA, in the 1930s, S. invicta is now the dominant ant throughout much of the southeastern United States, having outcompeted or displaced many other species of ants. Since their introduction, fire ants have infested more than $114 \times 10^{6}$ ha in the United States (Callcott and Collins 1996), numerous Caribbean Islands, and have recently invaded the state of California in the western United States, Australia, Taiwan, and China.

The potential negative impacts of red imported fire ants on wildlife species have been documented (Allen et al. 2004), although research is limited. Many species of wild animals are susceptible to both direct and indirect fire ant impacts. Ground-nesting species that lay eggs or produce altricial young may be especially vulnerable to direct impacts (Allen et al. 1995). Impacts include predation of newly hatching young as well as reduced weight gain and survival of offspring nonlethally stung by fire ants. Fire ants may affect ecosystems by changing or eliminating ecological processes such as seed dispersal (Zettler et al. 2001). Clearly a large number of native species are potentially affected by fire ants. However, it is not cost nor conservation efficient to treat all species as equally vulnerable, and to conduct experiments with each to assess that vulnerability. Therefore, it was determined that a relative risk assessment method was needed to narrow research and conservation action to focus upon those wildlife species most at risk from fire ants. 
Table 1. Elements of the ecologically-based hazard index for assessing the relative risk of different lifehistory characteristics to fire ant impacts. Fire ant impacts on wildlife, and characteristics that lead to vulnerability to fire ant impacts, are reviewed in Allen et al. (2004).

\begin{tabular}{lll}
\hline \hline Life-history characteristic & Safe & Vulnerable \\
\hline Reproduction & live-bearing & egg-bearing \\
Eggs & hard-shelled & soft-shelled \\
Nests & in trees & on ground \\
Foraging & aerial/arboreal & on ground \\
Young & precocious & altricial \\
Reproductive timing & fall and winter & spring and summer
\end{tabular}

\section{Study area and landscape}

The landscape of our example is the state of South Carolina, USA. Fire ants are widespread and well established in South Carolina, so our example focuses on quantifying the adverse impact of an established stressor. Other harmful invasive species that are likely to become established or expand their range in the near future in South Carolina include cogongrass (Imperata cylindrica), tropical soda apple (Solanum viarum), and hemlock wooly adelgid (Adelges tsugae), among many others. In incipient invasions, our methods of spatial risk assessment can be used to assess potential impacts prior to the widespread establishment of the stressor species by creating predicted distributions of the future range of the invasive species. By assessing the risks early in the course of invasion, more options for managing risks or mitigating damage may be available.

\section{Stressor models}

For our example, fire ants were sampled throughout the state of South Carolina. Sampling was stratified by ecoregion, e.g., sandhills, coastal plain, piedmont, mountains, and by South Carolina gap analysis landcover type developed from Landsat Imagery with a minimum resolution of $30 \mathrm{~m}$. Approximately 10 replicates in each landcover type in each region were sampled. Each habitat patch was sampled by establishing a linear transect consisting of multiple sample points. Sample points consisted of bait attractants and pitfall traps.

We modeled the presence/absence of the stressor, i. e., fire ants, as the dependent variable; independent predictor variables included habitat, soils, aspect, and landscape metrics such as patch size, shape, the Euclidean distance of the survey location to a development, the area of development at various buffer distances around each survey location, and the Euclidean distance of the survey location to a paved road. Some variables were recorded in the field at sample locations, whereas others were 
Fig. 1. Predicted fire ant distribution map (90\% probability) for the state of South Carolina, USA, based on stepwise logistic regression analysis of sampling data, 1999-2000. We modeled the presence/absence of the stressor, i.e., fire ants, as the dependent variable, and habitat, soils, aspect, and landscape metrics such as patch size, shape, the euclidean distance of the survey location to a development, the area of development at various buffer distances around each survey location, the euclidean distance of the survey location to a paved road, were independent predictor variables. Only habitat variables were significant predictors of fire ant occurrence.

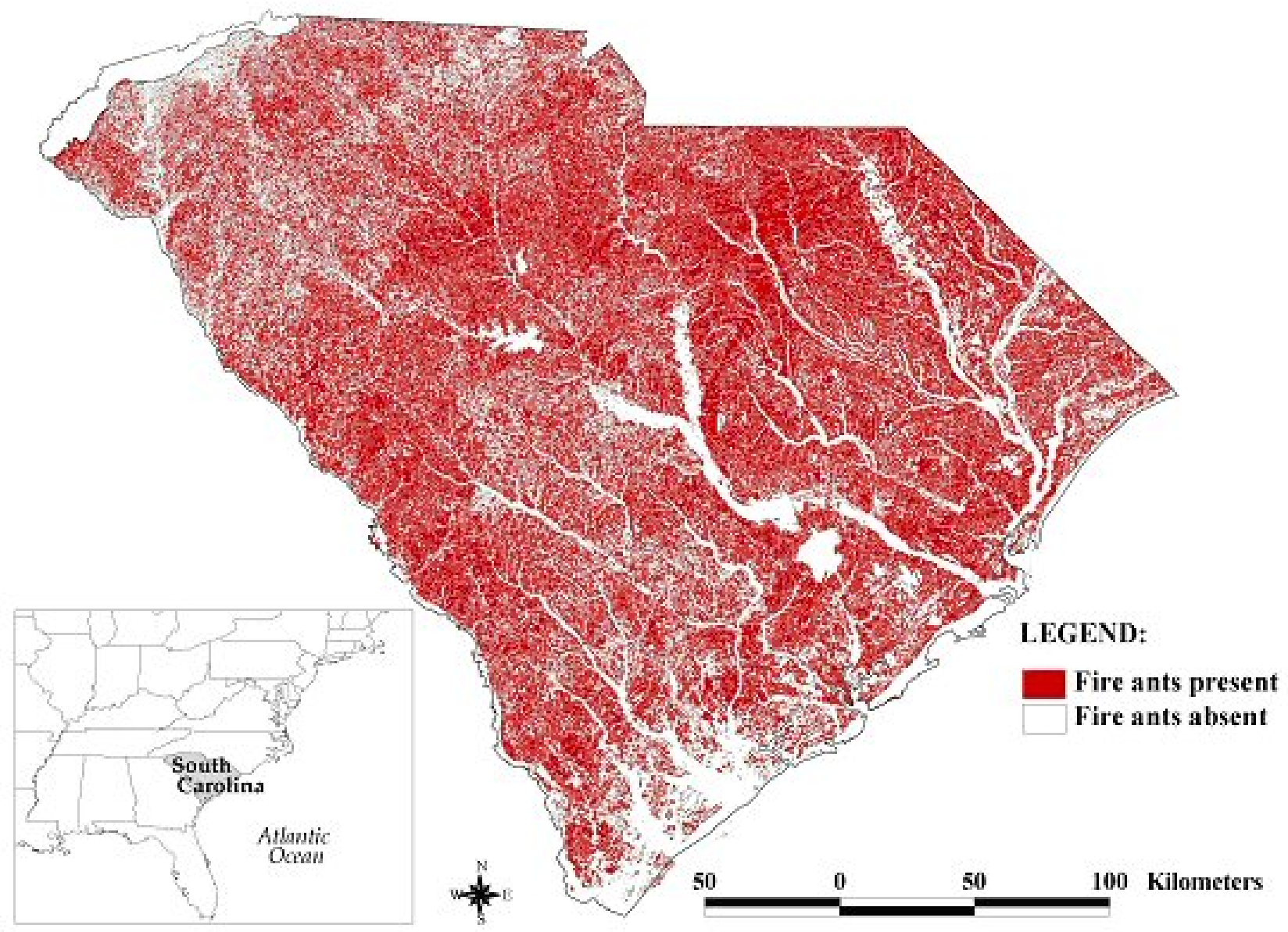

derived from soil and landcover maps available digitally. After evaluating and eliminating strongly collinear variables, the landscape variables were entered into a stepwise logistic analysis to derive a multivariate model that predicted the presence or absence of red imported fire ants. The resulting models were evaluated using goodness-of-fit tests based on maximum likelihood estimates and/or Akaike's information criterion (Akaike 1969, Burnham and Anderson 1998). We used three approaches to build predictive models of our stressors of interest: presence/absence models at two levels of probability of occurrence, i.e., modeling a species as "present" when there is a predicted $90 \%$ or $75 \%$ probability of presence based on statistical models, and models that produce a "probability of presence landscape" based on sample proportions, i.e., a coverage in which each grid cell is assigned a probability of presence of each stressor based on percent presence in any given 
Fig. 2. Predicted fire ant distribution map for the state of South Carolina, USA, based on calculated probability of fire ant encounter during fire ant sampling, 1999-2000. This model was produces a "probability of presence landscape" based on sample proportions, and is generated by assigning each grid cell a probability of presence of fire ants based on percent presence within any given habitat type.

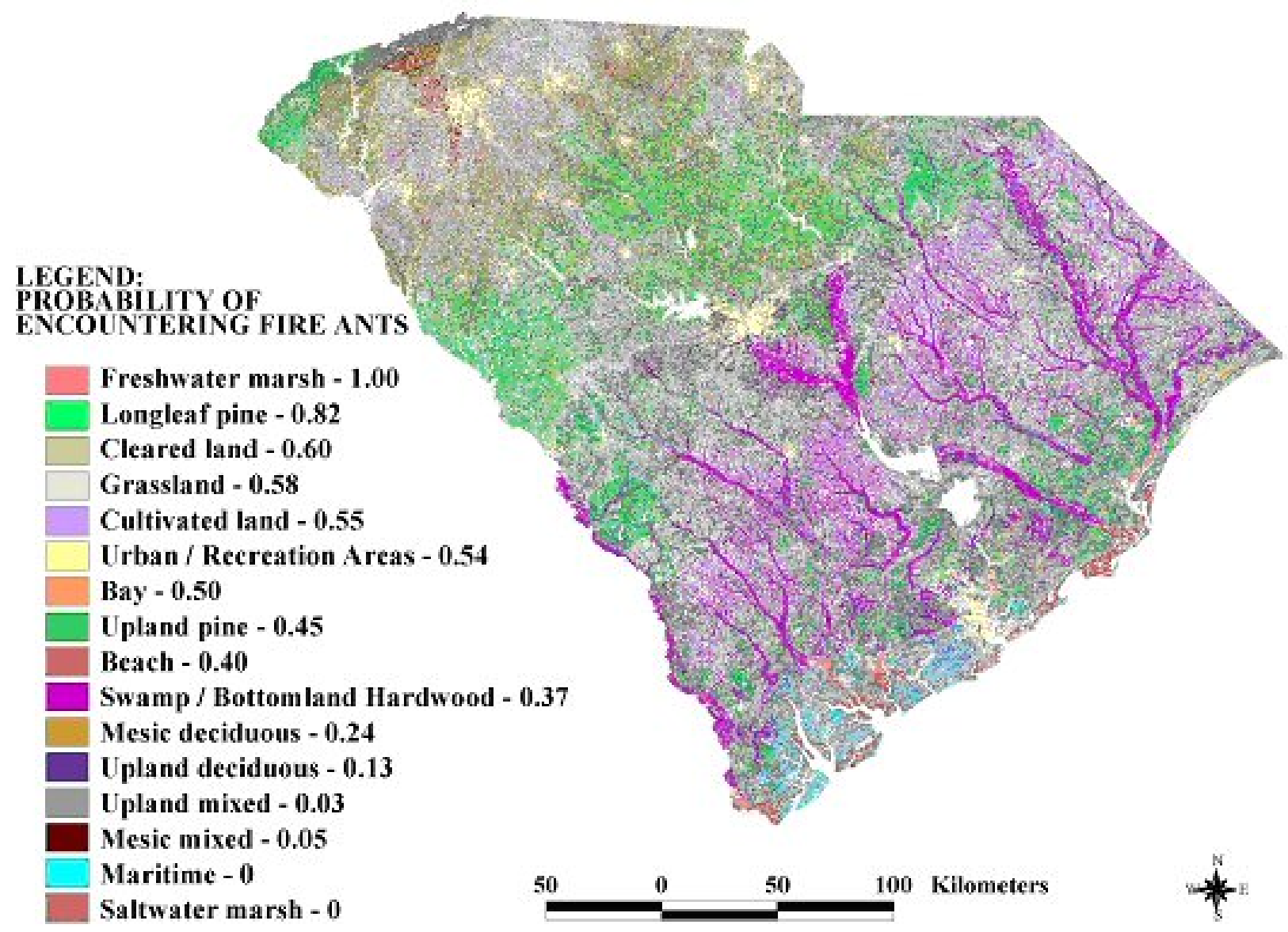

habitat (Figs. 1 and 2, respectively). In our example only habitat variables were significant in logistic models. The logistic model provides a binary map (Fig. 1) of fire ant presence, and the probability of presence approach provides a continuous map (Fig. 2 ), consistent with varying fire ant densities across regions and landcovers. The probability of encounter model provides a risk surface, but risk surfaces can be developed using either approach. Many other approaches are available for the modeling of stressor species distributions.

\section{Predictive models: targets}

We illustrate our example by using two at risk "listed" species. Listed species represent animals with small or declining populations, for which additional stressors may be a proximate cause of extinction. The common ground-dove (Columbina passerina) is associated with open habitats such as grasslands and savannas. It has been declining across much of its range, including South Carolina, where it is listed as threatened. In addition to habitat loss, fire ants have been speculated as a risk factor for this species (Cely 2000). The swallow-tailed kite 
Fig. 3. Spatial correspondence of common ground-dove (Columbina passerina) predicted distribution and red imported fire ant (Solenopsis invicta) predicted distribution in the state of South Carolina, USA, at a $30 \mathrm{~m}$ resolution. The map of the state threatened common ground-dove was based on predicted distribution model developed by the South Carolina Gap Analysis Program, an approach that models potential habitat within the known geographic range of a species. Red imported fire ant predicted distribution based on logistic regression analysis of statewide presence/absence ant sampling (Fig. 1). Eighty-three percent of common ground-dove's predicted distribution is shared with fire ants with spatial co-occurrence represented in blue.

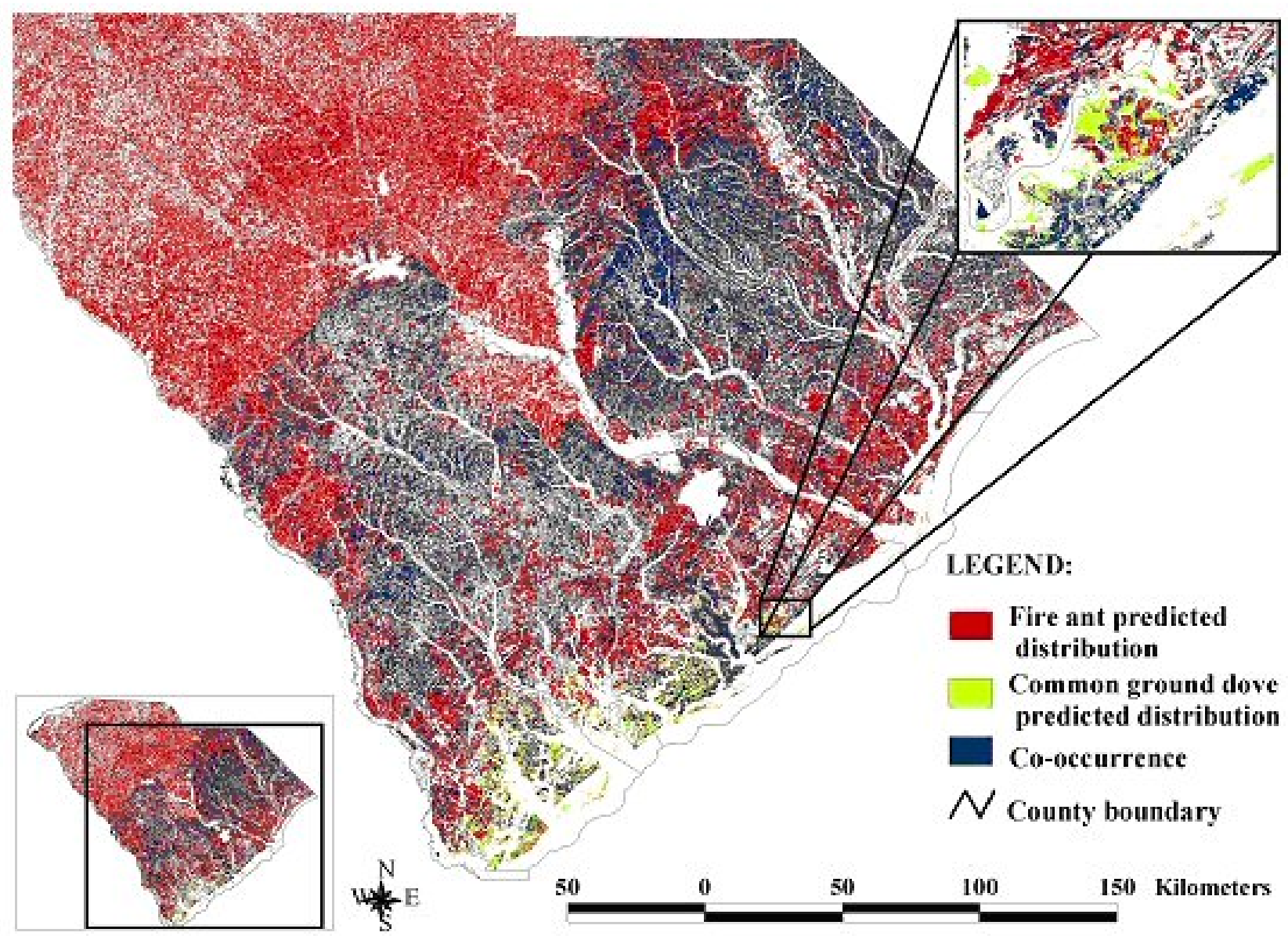

(Elanoides forficatus) is associated with forested wetlands. The regional population may be stable, but the species is listed as imperiled by The Nature Conservancy. The predominant identified threat is the loss of suitable nesting habitat.

For target species, we used the general specieshabitat models developed by the South Carolina Gap Analysis Project. Gap analysis models are created through a process that includes creating county range maps based on range data, developing a habitat matrix for each species based on known species-habitat associations, and incorporating the habitat affinity data with the land cover classification map (Scott et al. 1993). Because gap analysis projects are underway in all states in the USA, and species models are in the public domain once completed, these models offer the advantages 
Fig. 4. Spatial correspondence of swallow-tailed kite (Elanoides forficatus) predicted distribution and red imported fire ant (Solenopsis invicta) predicted distribution in South Carolina, USA, at a 30 m resolution. The map of the swallow-tailed kite based on predictive habitat model developed by the South Carolina Gap Analysis Program, an approach that models potential habitat within the known geographic range of a species. Red imported fire ant predicted distribution based on logistic regression analysis of statewide presence/absence ant sampling (Fig. 1). Seven percent of swallow-tailed kite's predicted distribution is shared with fire ants with spatial co-occurrence represented in blue.

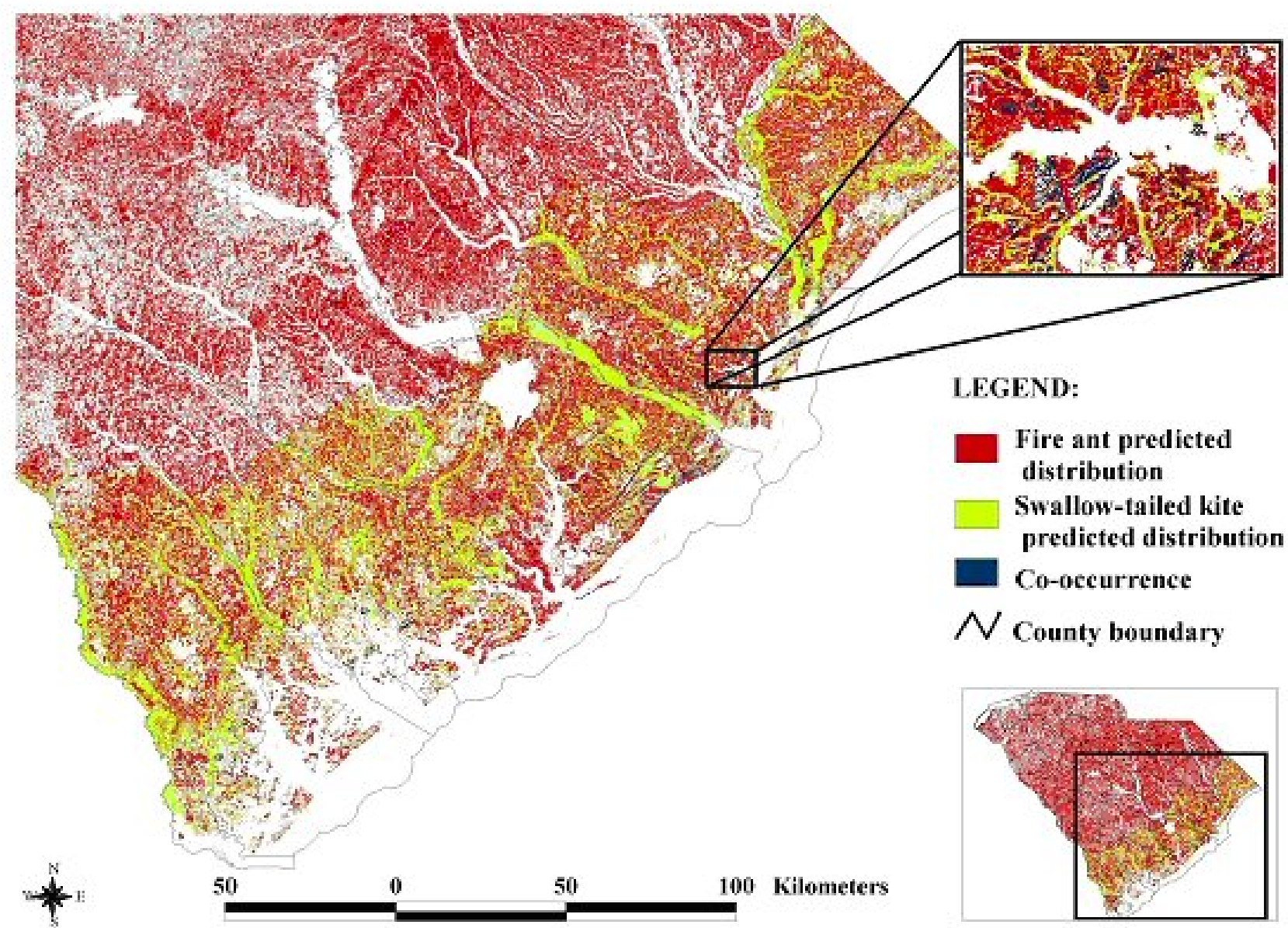

of being available and peer reviewed. Different states release models at different resolutions. In South Carolina species models are available at a 90$\mathrm{m}$ resolution.

In cases in which the stressor impact is severe, or in which the stressor has been present for an extended period, the stressor may have already had an influence on the spatial distribution of the target. In our example, target models are based on potential habitat, and, thus, not influenced by stressor distributions. 
Table 2. Calculation of hazard indices based on six life-history traits that potentially increase species' vulnerability to fire ant impacts. A "+" indicates vulnerability. Hazard indices are produced by dividing the number of hazards to which targets are vulnerable by the total number of potential hazards.

\begin{tabular}{lccccccc}
\hline \hline & & soft & ground & ground & altricial & spring/summer & hazard \\
& & & & & & & \\
\hline Species & ovipary & shelled & nesting & foraging & young & young & index \\
Common ground-dove & + & - & + & + & + & + & 0.83 \\
Swallow-tailed kite & + & - & + & - & + & + & 0.67 \\
& & & & & & & \\
\end{tabular}

\section{Characterization of ecological effects}

In our example, target species with altricial young, species that prefer open habitats, species that nest on the ground, and oviparous species are more susceptible to impacts from fire ants than those with precocious young, those that occupy closed canopy forests, those that nest high in trees, or those that are viviparous. Thus, species with the former attributes receive higher scores for that component of the overall hazard index (Table 1). This form of the index assumes additivity among the potential vulnerabilities.

\section{RISK CHARACTERIZATION}

The first spatial level of risk assessment is accomplished by overlaying the results of the predictive models of fire ant distribution with habitat-relationship models of listed species (Figs. 3 and 4). In doing so, we have characterized the probable co-occurrences of invasive and target species. The risk characterization phase combines the exposure, i.e., co-occurrence, and effects into an integrated estimate of risk. Risk is estimated as the product of the hazard index (Table 2) and probability of co-occurrence (Table 3). Although this is not directly interpretable in terms of predicted population-level consequences, it provides a comparable set of values, which allows ranking of target species in terms of the likely magnitude of impact. In this example, red imported fire ants are predicted to pose a greater risk to the common ground-dove than to the swallow-tailed kite. Note, that abundance data or reproductive success data for target organisms and the use of PVA models can easily be incorporated into this method, and lead to a spatially explicit index.

\section{DISCUSSION}

Our procedures provide managers an efficient and flexible tool for identifying species at risk and calculating relative risk across a suite of species, determining the spatial distribution of risk, and exploring landscape manipulations to reduce risk. This procedure results in a rapid spatially and ecologically based risk assessment that can incorporate multiple sources of uncertainty. It allows for an efficient filtering of species to determine relative risk to any stressor that can be spatially modeled. The explicit spatial nature of the assessment allows one to develop a general framework for evaluating how functional connectivity of habitat and other aspects of landscape patterns affect the risk faced by wildlife 
Table 3. Probability of spatial co-occurrence for two at risk species and fire ants in South Carolina as quantified by using a logistic regression derived fire ant distribution model and a probability of encounter fire ant distribution model. Overall risk index, shown in parentheses, is calculated as the product of the probability of co-occurrence and the hazard index.

Species

Probability of co-occurrence with fire ants based on logistic fire ant model
Probability of co-occurrence with fire ants based on probability-of-encounter fire ant model
Common ground-dove

Swallow-tailed kite
.8329 (risk index $=0.69$ )

.7210 (risk index $=0.48)$
.6354 (risk index $=0.53)$

.4025 (risk index $=0.27$ ) species from various types of stressors. This in turn allows for the determination of impacts of alternative land-use/landcover change scenarios on the distribution of stressors and the risk faced by wildlife species, and for the exploration of alternative landscape remedial and/or proactive actions to reduce that risk.

Land use or landcover changes affect the distribution of both invasive and native species. Scenario building anticipates the potential impacts of alternative futures. In our example, scenarios anticipating decreasing closed canopy forest area and increased open and disturbed habitats lead to increased distributions and abundances of fire ants. These same changes differentially affect target species. Closed canopy specialists will have decreased distributions and less core area and risk to fire ant impacts will increase. Open habitat specialists, such as the ground dove in our example, will have an increase in overall distribution, but the total area and proportion of range overlapping with fire ants will also increase, and risk will increase.

These methods are flexible in their application: in addition to their applicability for a broad class of stressors and targets, they are also equally applicable at a broad range of spatial scales, although they are most appropriate as a coarse filter at regional scales. These methods are potentially useful for risk managers in both the private and public sector at federal, state, and local scales. There is clear use for screening risks at broad scales, for example to determine risks faced by native wildlife across a landscape with the introduction of new diseases, and there is also usefulness to managers of conservation areas who may, for example, wish to determine the potential impacts of a new invasive species or wish to explore the effect of habitat manipulations on a stressor. When multiple stressors create management challenges, these methods will allow for the identification of the species most at risk, the stressors with the greatest impact, and habitat and landscape manipulations that may reduce impacts.

Our approach leads to a landscape spatial risk assessment of wildlife species to stressor impacts by investigating the spatial co-occurrence and ecology of stressors and target species of interest. After species potentially at risk because of spatial overlap are identified, the level of risk faced by a species is determined by incorporating ecological attributes of the target and stressor species, coupled with uncertainty analysis. Species judged to be facing significant risk may then be further investigated, allowing scarce resources to be spent only on those species identified as being most at 
risk. Further investigation may include experiments conducted in the laboratory or with manipulative field experiments, which may identify the most effective means of risk reduction for a particular species or stressor.

It is possible to account for the simultaneous impacts of multiple stressors on target species. To accomplish this, spatial models of stressors are overlaid and added in the same manner that species richness maps are created to investigate spatial patterns of species diversity, with consideration to whether stressor impacts are thought to be additive or not. Often, the nature of stressor interactions is not known, in which case an additive approach should be interpreted with caution. After creating multiple-stressor distributions, methods to investigate spatial co-occurrence among targets and stressors proceed largely as described above. For the simultaneous consideration of multiple stressors, hazard calculations and risk estimation also proceed as described above. Although this approach cannot readily account for interactions among stressors or targets, it does have utility in simultaneously assessing overall risks to targets from all known potential stressors.

Using neutral landscape models, With (2004) has investigated the role of disturbance and habitat fragmentation in promoting the spread of invasive species. The risk of invasive spread is dependent upon landscape features that affect dispersal and establishment. If the dispersal ability and demography of the invasive species can be estimated, this can be applied in identifying habitat patches at risk of invasion. Such patches must meet two basic requirements. They must be large enough to support a population of the invasive species, i.e., minimum critical area requirement, and be reachable by dispersal from other patches that serve as sources of colonizers, i.e., functional connectivity requirement. This logic has been applied to predicting the potential distribution of indigenous species (e.g., Johnson et al. 2004).

An approach that focuses on landscapes and that is explicitly spatial is of particular relevance as remaining undeveloped lands become increasingly restricted and isolated and more important in the management and recovery of species and ecological systems. Effective ecosystem management includes the control of invasive species and other stressors with large impacts, understanding where those impacts may be the most severe, and implementing management strategies to reduce impacts.

Responses to this article can be read online at: http://www.ecologyandsociety.org/voll1/iss 1/art39/responses/

\section{Acknowledgments:}

Funding was provided by the Enhancement of Research and Extension Programs in Imported Fire Ant Biology, Clemson University, USA. The South Carolina Cooperative Fish and Wildlife Research Unit is jointly supported by a cooperative agreement among the United States Geological Survey, the South Carolina Department of Natural Resources, Clemson University, and the Wildlife Management Institute. An earlier version of this manuscript was improved by comments from A. Garmestani and B. Weeks.

\section{LITERATURE CITED}

Akaike, H. 1969. Fitting autoregressive models for prediction. Annals of the Institute of Statistical Mathematics 21:243-247.

Allen, C. R., D. Epperson, and A. Garmestani. 2004. The impacts of fire ants on wildlife: a decade of research. American Midland Naturalist 152:88-103.

Allen, C. R., R. S. Lutz, and S. Demarais. 1995. Red imported fire ant impacts on northern bobwhite populations. Ecological Applications 5:632-638.

Allen, C. R., Pearlstine L. G., Wojcik D. P., and W. M. Kitchens. 2001. The spatial distribution of diversity between disparate taxa: spatial correspondence between mammals and ants. Landscape Ecology 16:453-464.

Andersen, M. C., H. Adams, B Hope, and M. Powell. 2004. Risk assessment for invasive species. Risk Analysis 24:787-793.

Bartell, S. M., and S. K. Nair. 2004. Establishment risks for invasive species. Risk Analysis 24:833-845.

Burnham, K.P., and D. R.Anderson. 1998. Model 
selection and inference: a practical informationtheoretic approach. Springer-Verlag, New York, New York, USA.

Callcott, A-M., and H. L. Collins. 1996. Invasion and range expansion of imported fire ants (Hymenoptera: Formicidae) in North America from 1918-1995. Florida Entomologist 79:240-251.

Cely, J. E. 2000. Status and distribution of the common ground-dove in South Carolina. The Chat 64:37-46.

Clark, L. A., and D. Pregibon. 1992. Tree-based models. Pages 377-419 in J. M. Chambers and T. J. Hastie, editors. Statistical models. Wadsworth and Brooks/Cole, Pacific Grove, California, USA.

Environmental Protection Agency (EPA). 1998. Guidelines for ecological risk assessment. EPA/630/R-95/002F. Washington, D.C., USA.

Foran, J. A., and S. A. Ferenc, editors. 1999. Multiple stressors in ecological risk and impact assessment. SETAC Press, Pensacola, Florida, USA.

Forys, E. A., C. R. Allen, and D. P. Wojcik. 2002. Influence of proximity and amount of human development and roads on the occurrence of the red imported fire ant in the Lower Florida Keys. Biological Conservation 108:27-33.

Groves, R. H., F. D. Panetta, and J. G. Virtue. 2001. Weed risk assessment. CSIRO, Collingwood, Australia.

Hayes, K. R. 2002. Identifying hazards in complex ecological systems. Part 1: fault-tree analysis for biological invasions. Biological Invasions 4:235-249.

Iverson, L. R., and A. M. Prasad. 1998. Predicting abundance of 80 tree species following climate change in the eastern United States. Ecological Monographs 68:465-485.

Johnson, A. R., C. R. Allen, and K. A. N. Simpson. 2004. Estimating functional connectivity of wildlife habitat and its relevance to ecological risk assessment. Pages 41-55 in L. A. Kaputska, H. Galbraith, M. Luxon, and G. R. Biddinger, editors. Landscape ecology and wildlife habitat evaluation: critical information for ecological risk assessment, land-use management activities and biodiversity enhancement practices. ASTM STP 1458. West Conshohocken, Pennsylvania, USA.

Landis, W. G., and J. A. Wiegers. 1997. Design considerations and a suggested approach for regional and comparative ecological risk assessment. Human and Ecological Risk Assessment 3:287-297.

Landis, W. G. 2004. Ecological risk assessment conceptual model formulation for nonindigenous species. Risk Analysis 24:847-858.

Li, W., Z. Wang, Z. Ma, and H. Tang. 1997. A regression model for the spatial distribution of redcrown crane in Yancheng Biosphere Reserve, China. Ecological Modelling 103:115-121.

Mack, M. C., and C. M. D'Antonio. 1998. Impacts of biological invasions on disturbance regimes. Trends in Ecology and Evolution 13:195-198.

Pearce, J., and S. Ferrier. 2000. An evaluation of alternative algorithms for fitting species distribution models using logistic regression. Ecological Modelling 128:127-147.

Pheloung, P.C., P. A. Williams, and S. R. Halloy. 1999. A weed risk assessment model for use as a biosecurity tool evaluating plant introductions. Biological Conservation 57:239-251.

Pimentel, D., L. Lach, R. Zuniga, and D. Morrison. 2000. Environmental and economic costs associated with non-indigenous species in the United States. BioScience 50:53-65.

Scott, J. M., F. Davis, B. Csuti, R. Noss, B. Butterfield, C. Groves, H. Anderson, S. Caicco, F. Derchia, T. C. Edwards, Jr., J. Ulliman, and R. G. Wright. 1993. Gap analysis: a geographical approach to protection of biological diversity. Wildlife Monographs 123.

Seife, C. 2003. The Columbia disaster underscores the risky nature of risk analysis. Science 299:1001-1002.

United States Department of Agriculture (USDA). 1993. Pest risk assessment of the importation of Pinus radiata, Nothofagus dombeyi, and Laurelia philippiana logs from Chile. U.S. Forest Service Miscellaneous Publication Number 1517. U.S. Forest Service, Washington, D.C., USA. 
United States Fish and Wildlife Service (USFWS/ NOAA). 1996. Report to the Aquatic Nuisance Species Task Force. Generic nonindigenous aquatic organisms risk analysis review process. Washington, D.C., USA.

Vitousek, P. M., C. M. D’Antonio, L. L. Loope, and R. Westbrooks. 1996. Biological invasions as global environmental change. American Scientist 84:468-478.

With, K. A. 2002. The landscape ecology of invasive spread. Conservation Biology 16:1192-1203.

With, K. A. 2004. Assessing the risk of invasive spread in fragmented landscapes. Risk Analysis 24:803-815.

Wojcik, D. P., C. R. Allen, R. J. Brenner, E. A. Forys, D. P. Jouvenaz, and R. S. Lutz. 2001. Red imported fire ants: impact on biodiversity. American Entomologist 47(1):16-23.

Zettler, J. A., T. P. Spira, and C. R. Allen. 2001. Ant-seed mutualisms: can fire ants sour the relationship? Biological Conservation 101:249-253. 